\title{
Babies and Bath Water
}

\author{
Kathryn Flannery
}

[I]t may be hypothesized that examination of the contexts and uses of literacy in communities today may show that there are more literacy events which call for appropriate knowledge of forms and uses of speech events than there are actual occasions for extended reading and writing.

-Shirley Brice Heath, "Protean Shapes in Literacy Events" (351 original emphasis)

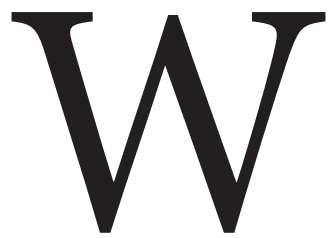

e had just begun our discussion of Shirley Brice Heath's "Protean Shapes in Literacy Events" in my upper division Uses of Literacy course when a conscientious and eager sophomore, Sarah, asked what Heath meant by "extended reading and writing." Sarah, who is planning to be a high school teacher, was trying to figure out the distinction Heath seems to be making between everyday literacies and schooled literacies. We had already read Brian Street's critique of the so-called "essay-text" tradition, so we were not coming to Heath cold (Street 116). Class members had also noticed as they kept their daily literacy logs that in their ordinary lives they engaged in reading and writing of many forms and uses. Perhaps "back then," Sarah surmised, when Heath was writing in the 1980s, students in high school and college were actually engaged in something like extended-by which Sarah meant longer, more demanding-reading and writing. But Sarah was disappointed to find that relatively little was expected of her in school: she had written very little in high school and not much more in college; and reading seemed only supplementary to class lectures with college instructors often supplying, electronically or on paper, what she referred to as "note sheets" outlining the lecture or simplifying information from textbooks. Other students entered into the conversation, adding their own experiences. A few students had composed honors theses in high school and some had been assigned research papers in college History or English classes, but for the most part these students, ranging from sophomores to fifth-year seniors, recalled little that they would call "extended" literacy whether in discussion-size classes or large lectures. Outside of school, a few wrote poetry, song lyrics, or short fiction on their own; and a few characterized themselves as avid readers, reading for pleasure or inspiration across a range of genres. But for the most part students reported having had little experience, in school or out, with reading and writing that they thought required deep thought or concentration, time or challenge. Not all students shared Sarah's sense of regret, however. An older returning student, Sam, suggested that perhaps Street's critique had actually had some effect, to the extent that schooled literacy had "evolved" to be much like everyday literacy, characterized as he put it by short bits of text to read or to write. As they discovered in keeping their literacy logs, the most frequent action taken throughout the day was not extensive reading or writing, but "checking" and "scanning." But, is it such a bad thing, Sam asked, if 
what we do in school is more like the "real world"?

As I reflect on this class discussion and others like it, a number of questions arise. What is it that Sarah thinks she is missing? Of what value is extended reading and writing, however we might define those terms? What kinds of knowledges or know-how can we reasonably expect from extended reading and writing? Whether or not "real world" literacy involves primarily reading and writing short bits of text (through whatever modalities), to what extent should schools and universities shape curriculum to mirror the "real world" and whose "real world" gets to count? Much research in Literacy Studies has suggested that schools need to be more permeable to the larger community. But for such permeability to be productive, we would have to pay attention, in Heath's terms, to the specificity of concrete contexts in which reading and writing take place in order to better understand the personal and communal values and purposes of different kinds of practices. In the early 1980s, Heath was contesting what she saw as the dominant "dichotomous view of oral and literate traditions" (348). Her ethnography of communities in the Piedmont region of the Carolinas-the basis for her groundbreaking Ways with Words-led her to suggest that the presumed distinction between oral and literate groups might not in fact accurately describe the communicative practices evident in many communities in the United States. Her work contributed to a larger critique of those dominant notions of literacy that not only privilege so-called literate cultures over so-called oral cultures, but that privilege academic forms and practices over all others. Heath emphasizes the importance of knowing "what the framing situations for literacy events are in a variety of contexts" because they may differ significantly, and "in fact, contradict such traditional expectations of literacy as those taught in school or in job training programs" (351). This is a core idea that has generated much important work in Literacy Studies: traditional school-based literacies are not necessarily required on the job, in our personal lives, or in the day-to-day workings of the world. They do not, in and of themselves, guarantee economic success, moral superiority, or personal happiness. To take such school-based literacy as the measure of all literacies may thus blind us to the greater variety of literacy practices in the world-including the extent to which literacy and orality are intertwined-and to the greater capacity of ordinary people to engage in a variety of literacy events. The implications for both schooling and job training are significant. If, as in Heath's study, we notice the differing ways children engage in literacy practices outside of school, we might design our curriculum to build on what they already know how to do rather than presume cognitive deficits. A greater number of children might then succeed in school such that they would have more, rather than fewer, options in life. If, as in Sheryl Gowen's study of hospital workers, we appreciate the extent to which the janitor is already engaged successfully in a range of literacy practices (and in multiple modalities) outside of the workplace, we might design a job training program that starts with what he already knows how to do and, from there, build knowledges and skills not only actually useful for his present job, but potentially allowing him to move to a better job.

In neither case, however, is it presumed that what one does in school should be narrowly vocational or reductively skills-oriented or that it should merely replicate the literacies already available in the community. Heath does not argue that the literacies available to children in the communities she studies-whether working class or middle class, whether white or black-are sufficient in them- 
selves for the changing world in which they live. Gowen values the knowledges and the know-how the janitor makes use of as an active member of his church, but she does not assume those literacies are by themselves sufficient for him to advance on the job. In both cases, the literacies are shown to be specific to contexts even as they are powerful indicators of the capacity to learn more, to increase one's repertoire, to increase one's mobility between and among differing contexts.

If Literacy Studies thus provides Sam some support for his thinking, it also provides some support for Sarah's worry. Literacy Studies makes clear that everyday literacies are not necessarily "lesser"-they can enable us to perform all kinds of functions in our lives-but Literacy Studies also makes clear that everyday literacies may not be enough, and in some cases may be limiting or downright dysfunctional. In their very useful review of research concerning literacy and learning outside of school, Glynda Hull and Katherine Schultz do not doubt the value of "document[ing] and validat[ing] the plethora of personal and local literacy practices;" but, as important as that work continues to be, they urge that we "should not abandon the opportunities that school historically has provided to develop particular forms of text-based expertise, forms that provide a power absent in many everyday literacies" (602). Although they emphasize the value of schooling that "prepare[s] students for professional lives in which the mastery of written genres is central" (601), Hull and Schultz want to consider broader purposes beyond the narrowly vocational. They thus ask, "what forms of schooled literacy are powerful intellectual tools appropriate for these new times, and what forms are mere conventions or historical artifacts?" (602).

I take this to be a live, rather than merely rhetorical, question. Hull and Schultz do not assume that conventionalized forms with long histories cannot serve as powerful intellectual tools. They suggest, for example, that "essayist texts" might be valuable in part because they contrast with the short bits that "make up much everyday reading and writing in terms of form and purpose" (602). The phrase "essayist texts" in Literacy Studies has tended to serve as a placeholder for something like "academic writing," not one form but a polymorphous set of forms and practices. Although the phrase is sometimes taken to refer only to "essays" (as something like the equivalent to the critique of the five-paragraph theme in Composition Studies), Hull and Schultz offer a more capacious understanding that encompasses not only essays (an already protean category), but forms of imaginative writing as well. The problem with "essayist texts" comes not with a form or set of forms per se, however, but with the tendency to treat these forms or practices as valuable in and of themselves, independent of their history of use, as if-in Brian Street's strong form of the critique-such literacy was a neutral, rather than "culture-specific," practice (116). That particular forms or practices come with historical_or culture-specific_baggage does not immediately disqualify them for use in the present, however. It is not news to say that the master's tools have been used against him.

Hull and Schultz's question, then, might need to be refined: we need to ask not simply what forms of schooled literacy are powerful intellectual tools, but under what circumstances can forms and practices of literacy serve as powerful tools, how can they be taken up, appropriated or adapted for powerful use? Hull and Schultz foreground "length" as a distinguishing factor. Length alone, of course, is not sufficient, but one can imagine that length—as Sarah put it in our class discussion—can give one space and time to pursue a complex question or problem more deeply. That academic writ- 
ing "contrasts sharply" with typical forms in the everyday-Hull and Schultz mention "lists, letters, notes, advertisements" as examples of the everyday-can open up room for critical distance (602). In this sense, "contrast" may be necessary to defamiliarize routinized practices (whether routinized in school or out) (602). But perhaps most important is purpose.

Some of my students' analyses of key literacy events in their lives attest to traditional forms of reading and writing that have mattered to them as individuals and members of communities. The purposes they bring to "essayist texts" or that they discover through reading and writing do not simply replicate the purposes the institution, the curriculum, or their teachers necessarily have in mind. For some students, traditional literacy practices connect them to the past, to their families or longer traditions in powerful ways. Joseph first learned to pray by rote in Hebrew School, without fully understanding, but he came to value this ancient practice because it connects him to his father, his grandfathers, on back through multiple generations. This connectedness fuels his desire to study Hebrew, not for his job but for his life. After Emily read "all of!" Darwin's Origin of Species, she wrote a paper on what she thought was Darwin's "reverence" for the natural world, a reverence that allowed her to be in conversation with a book she had been taught to see as opposed to everything her religion held sacred. She was proud of the fact that she now had an independent view and could now hold her own in a dinner table conversation with her uncle who first encouraged her to go to a secular college (against her parents' objections). Other students have deployed "academic writing" to get a stronger hold on forms of discourse from the world of work or from their everyday lives; and still others have achieved some critical traction with everyday forms that at first seemed unalterable. Adam, an older returning student who never thought he was a "good writer" and never thought he would need to write much of anything in his adult life, nonetheless found himself in a job that required composing technical reports for which his schooling had not prepared him. He was surprised to find that his technical expertise actually enabled him to improve on boilerplate formats he was expected to use, and in the process he discovered that he is, as he put it, more than just a "robot" filling in the blanks.

Here are a range of purposes-not manufactured by a curriculum or necessarily even anticipated by teachers-representing ways students have put forms of schooled literacies to use. But what about Sarah and the increasingly greater number of students who report that they have not had such opportunities for purposeful engagement in extended reading and writing, in school or out? Composition cannot by itself insure that students will have the time and space to try out a range of intellectual tools, to weigh the conventions, to put academic forms in relation to the literacies of the everyday in order to interrogate both. The university as a whole has that responsibility. But Composition Studies has historically attempted both to critique institutionalized practices and also to show how and in what ways those practices have value for students personally and professionally, and for the larger community. Composition Studies, in this sense, has been invested, from the outset, in keeping the university permeable to the outside. It may be, however, that sometimes in our efforts to insure that the everyday gets a fair hearing, we have risked losing the power of difference, the power of contrast, the power of academic literacies in relation to the everyday. We are at our best, I would say, when we resist romanticizing either everyday literacies or schooled literacies. And we are most honest when we recognize the potential power in the intellectual tools we ourselves have 
used to mount critiques of the academy and of the larger culture. Especially in our increasingly less mobile society, it is all the more important-in a Gramscian sense-to insure that all students have access to a range of literacies that they can take up and redeploy in ways beyond their own or our own imaginings. To presume that only certain kinds of students will "need" or can effectively make use of extended reading and writing is to risk rigidifying social and political stratifications already too much in place.

University of Pittsburgh

\section{WORKS CITED}

Gowen, Sheryl. The Politics of Workplace Literacy: A Case Study. New York: Teachers College P; 1992. Print.

Heath, Shirley Brice. "Protean Shapes in Literacy Events: Ever-Shifting Oral and Literate Traditions." Perspectives on Literacy. Eds. Eugene R. Kintgen, Barry M. Kroll, and Mike Rose. Carbondale: Southern Illinois UP, 1988. 348-370. Print.

Hull, Glynda, and Katherine Schultz. "Literacy and Learning Out of School: A Review of Theory and Research." Review of Educational Research 71.4 (2001): 575-611. Print.

Street, Brian V., and Adam Lefstein. Literacy: An Advanced Resource Book for Students. London: Routledge, 2007. Print. 